\title{
Development and functional morphology of the foreguts of larvae and postlarvae of three crustacean decapods
}

\author{
Abrunhosa, F* and Melo, $M$. \\ Núcleo de Estudos Costeiros, Universidade Federal do Pará - UFPA, \\ Alameda Leandro Ribeiro, Bairro Aldeia, CEP 68600-000, Bragança, PA, Brazil \\ *e-mail: faraujo@ufpa.br \\ Received April 6, 2006 - Accepted September 1, 2006 - Distributed February 29, 2008 \\ (With 7 figures)
}

\begin{abstract}
The development of the foregut structure and the digestive function of the decapods Litopenaeus vannamei, Sesarma rectum and Callichirus major larvae and post larvae were examined. The protozoeal foregut of L. vannamei is simple, lacking a cardiopyloric valve and bearing a rudimentary filter press. In mysis, the filter press is more developed. In the juvenile stage, grooves and a small lateral tooth arise. In S. rectum, the foregut has a functional cardiopyloric valve and a filter press. The megalopal and juvenile stages of this species have a gastric mill similar to those in adult crabs. In C. major, the foregut of the zoeae is specialized, with the appearance of some rigid structures, but no gastric mill was found. Calcified structures are observed in the megalopae and they become more developed in the juvenile stage. The results support suppositions, previously reported in other studies, that feeding behavior of each larval and postlarval stage is directly related to the morphological characteristics of the foreguts.
\end{abstract}

Keywords: foregut, Litopenaeus vannamei, Sesarma rectum, Callichirus major, morphology.

\section{Desenvolvimento e morfologia funcional dos estômagos de larvas e pós-larvas de três crustáceos decápodes}

\begin{abstract}
Resumo
O desenvolvimento da estrutura do estômago e da função digestiva foi examinada em larvas e pós-larvas de Litopenaeus vannamei, Sesarma rectum e Callichirus major. O estômago do protozoea de L. vannamei é muito simples, sem válvula cárdiopilórica e apresenta um filtro pilórico rudimentar. Em mysis, o filtro pilórico parece ser mais desenvolvido. No juvenil I surgem calhas e dentes laterais pouco desenvolvidos. Os estômagos dos zoeae de $S$. rectum possuem a válvula cárdiopilórica e o filtro pilórico funcionais. Nos estágios megalopa e juvenil I o moinho gástrico é complexo. Em $C$. major, os estômagos dos zoeae se mostram especializados exibindo algumas estruturas rígidas, mas não apresentam moinho gástrico. Esta estrutura surge no megalopa e juvenil I. Os resultados suportam suposições anteriores que o comportamento alimentar de larvas e pós-larvas está diretamente relacionado com as características morfológicas dos estômagos.
\end{abstract}

Palavras-chave: estômago, Litopenaeus vannamei, Sesarma rectum, Callichirus major, morfologia.

\section{Introduction}

The features and functionality of the foreguts of decapod crustaceans were extensively examined in adult specimens, in the attempt to understand the digestive mechanism of each studied species (Meiss and Norman, 1977; Kunze and Anderson, 1979; Suthers, 1984; Skilleter and Anderson, 1986; Mikami and Takashima, 1993; Pinn et al., 1999; Jha and Homechaudhuri, 2001; Brösing et al., 2002; Castro and Bond-Buckup, 2003). But, little information was achieved for larvae and postlarvae of crustaceans.

Information about the morphological development of foreguts and feeding appendages has contributed to the identification of an adequate diet in larval culture and, consequently, increasing the survival rate during the larval development (Nishida et al., 1990; Minagawa and Takashima, 1994; Abrunhosa and Kittaka, 1997a).

Evidences of non-feeding behavior were observed for cultured larvae during the entire transitory stage (puelurus) for various species of the genera Panulirus, Jasus and Palinurus (Kittaka, 1988; 1994; Kittaka and Ikegami, 1988; Kittaka et al., 1997). Non-feeding behaviour in pueruli has been consistent with Nishida et al. (1990), Wolfe and Felgenhauer (1991), Mikami and Takashima (1993) and Lemmens and Knott (1994), in 
which substantial morphological changes occurred in the digestive system during metamorphosis by the reduction of mandibles and the number of setae in the mouthpart appendages and poorly developed foreguts.

Abrunhosa and Kittaka (1997a,b) reported similar observations during non-feeding stages in megalopae (transitory stage) of Paralithodes crabs (an important fishing resource of the Northern Pacific) related to the poorly developed feeding appendages (mouthparts and foregut) and, more recently, during the zoeal stages of the thalassinid Lepidophthalmus siriboia Felder and Rodrigues, 1993. (Abrunhosa et al., 2006).

The present study supplies morphological descriptions of foreguts of larvae and post-larvae of three species belonging to the infra-order of Pleocyemata, Callicurus major (Say, 1818) (Thalassinidea) and Sesarma rectum Randall, 1840 (Brachyura) and Dendrobranchiata, Litopennaeus vannamei (Boone, 1931) (Penaeidea). The structural organization of the studied foreguts is compared with other decapods and the relationship between the foregut morphology and individual feeding behaviour is discussed.

\section{Material and Methods}

\subsection{Obtaining of the larvae and post-larvae}

\subsubsection{L. vannamei}

The larval stages and juvenile I were obtained from donation by the laboratory of larviculture of Marine Aquacrusta Ltda company, located in the state of Ceará, in May 2004.

\subsubsection{C. major and S. rectum}

The larvae and post-larvae were obtained in previous larval rearing accomplished by the laboratory of crustacean larviculture of the Federal University of Pará, Campus of Bragança in March 2004. Samples of the larval and post-larval stages were identified following the descriptions of Rodrigues (1976) for C. major and Fransozo and Hebling (1986) for $S$. rectum.

\subsection{Samples}

Ten individuals of each stage of $L$. vannamei (Protozoea I, and Mysis I and III and juvenile I), C. major (Zoea I and IV, megalopa and juvenile I) and S. rectum (Zoea I and IV, megalopa and juvenile I) previously described were fixed in formalin solution $10 \%$ (v/v). The nauplii of L. vannamei were not investigated in this study, because according to Lovett and Felder (1989) the individuals lacked foregut in this stage.

\subsection{Treatment for dissection of foregut}

The samples were immersed in aqueous solution of potassium hydroxide (KOH) $5 \%$ and heated to $80^{\circ} \mathrm{C}$. Then, the individuals were washed in distilled water and immersed in an ethyl alcohol 70\% + glycerol (1:1) solution.

\subsection{Dissection, illustration and description of the foregut}

After dissection, the individuals were placed in slides with ethyl alcohol $70 \%+$ glycerol $(1: 1)$. The dis- section was made with fine needles (BD Ultra-Fine ${ }^{\circledR}$, $12.7 \times 0.33 \mathrm{~mm}$ ) under an optical microscope Zeiss. The foreguts were removed and transferred to another slice where, they were stained with aqueous solution of metilene blue $1 \%$.

The foreguts were observed in lateral, dorsal and ventral view, and illustrated in right lateral view aided by a micrometer scale. The terminology used in the description follows Meiss and Norman (1977), Nishida et al. (1990), Abrunhosa and Kittaka (1997a) and Abrunhosa et al. (2003).

\section{Results}

\subsection{Gross morphology of foregut of larvae and post-larvae}

\subsubsection{L. vannamei}

\section{Protozoea I}

The foregut of this stage was not described, due to the impossibility of observation under an optical microscope.

\section{Protozoea III (Figure 1a)}

Foregut simple; chitinous; lacking hard structure; total length about $0.24 \mathrm{~mm}$.

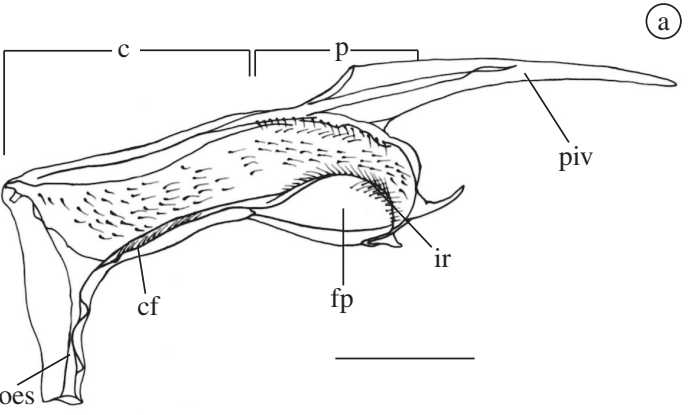

(b)

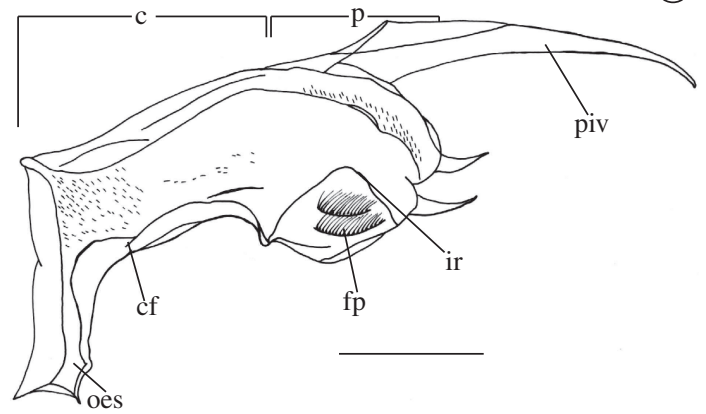

Figure 1. Litopenaeus vannamei, Foregut of larvae in lateral view (right side). a) protozoea III; and b) mysis I; scale bar $=0.05 \mathrm{~mm}$. Abbreviations: $\mathrm{c}=$ cardiac chamber; $\mathrm{cf}=$ cardiac chamber floor; $\mathrm{cpv}=$ cardiopyloric valve; $\mathrm{fp}=$ filter press; ir = interampullary crista; oes = oesophagus; $\mathrm{p}=$ pyloric chamber; piv = intestinal pyloric valve. 
Cardiac chamber: narrow and elongate; numerous fine and short setae filling every wall and base of cardiac floor; cardiopyloric vestigial and unarmed.

Pyloric chamber: narrow, with numerous small setae in the cardiac roof and wall; pyloric intestinal valve very elongated; filter press lacking filtration net but, with 2 blisters filling all inferior portion of the chamber bearing some setae in posterior portion; the interampullary crista with a roll of small setae in superior portion.

\section{Mysis I (Figure 1b)}

Foregut chitinous; lacking hard structures; total length approximately equal to the protozoea III.

Cardiac chamber: narrow and elongate with micro setae filling the anterior portion of the cardiac wall; cardiac floor lacking setae and brush; cardiopyloric valve almost vestigial and unarmed.

Pyloric chamber: With micro-setae in the pyloric roof; intestinal elongate pyloric valve, similar to protozoea III; filter press enlarged filling all inferior portion of the pyloric chamber and visibly more developed compared to previous stage; ampullary crista lacking setae.

\section{Mysis III (Figure 2a)}

Foregut more specialized than mysis I, but without rigid structures; total length about $0.30 \mathrm{~mm}$.

Cardiac chamber: Narrow; elongate and bent; short setae filling the cardiac wall anteriorly; cardiac floor bearing a ventral brush; cardiopyloric valve prominent but unnamed.

Pyloric chamber: Lacking setae in the cardiac floor and wall; intestinal pyloric valve elongate; filter press more developed than mysis I; interampullary crista with a roll of setae.

\section{Juvenile I (Figure 2b)}

Foregut more complex compared to previous stages; showing some unclearly distinct ossicles; total length about $0.32 \mathrm{~mm}$.

Cardiac chamber: Bent and narrow, with gutters in the chamber; cardiac floor with rows of setae; showing some hard structures but almost unidentified; cardiopy- loric valve rounded, lacking setae and supported by a bent unidentified ossicle.

Pyloric chamber: more enlarged with some medium setae in the cardiac wall; pyloric intestinal valve elongate; lateral pyloric valve bigger than those of previous stages; filter press filling all inferior portion of pyloric chamber; setae arranged in rows in the interampullary crista.

\subsubsection{C. major}

\section{Zoea I (Figure 3a)}

Foregut showing some hard structure; total length $0.46 \mathrm{~mm}$

Cardiac Chamber: with numerous fine setae filling the wall, roof and floor of the cardiac chamber; cardiopyloric valve prominent having hard structures in the inferior portion and armed with numerous fine setae in the posterior and superior portions.

Pyloric chamber: well-developed, with reduced setae in the roof and wall; pyloric intestinal valve elongate; some ossicles easily visible, such as: pleuropyloric and inferior posterior pyloric; filter press wide and complex filling the inferior portion of the pyloric chamber; interampullary crista lacking setae; ampullary net complex and functional.

\section{Zoea IV (Figure 3b)}

Foregut more developed compared to previous stages with some hard structures; total length $0.62 \mathrm{~mm}$.

Cardiac chamber: very setose, mainly in the wall and roof of the cardiac chamber; main brush well-developed; cardiopyloric valve prominent with the rigid structures more distinct in the inferior area and, equipped with medium setae in the posterior and superior portions.

Pyloric chamber: with numerous setae in the roof and the wall of the pyloric chamber, mainly in the inferior and posterior portions; pyloric intestinal valve elongate; filter press wide, specialized and complex, occupying all inferior portion of the chamber; several setae
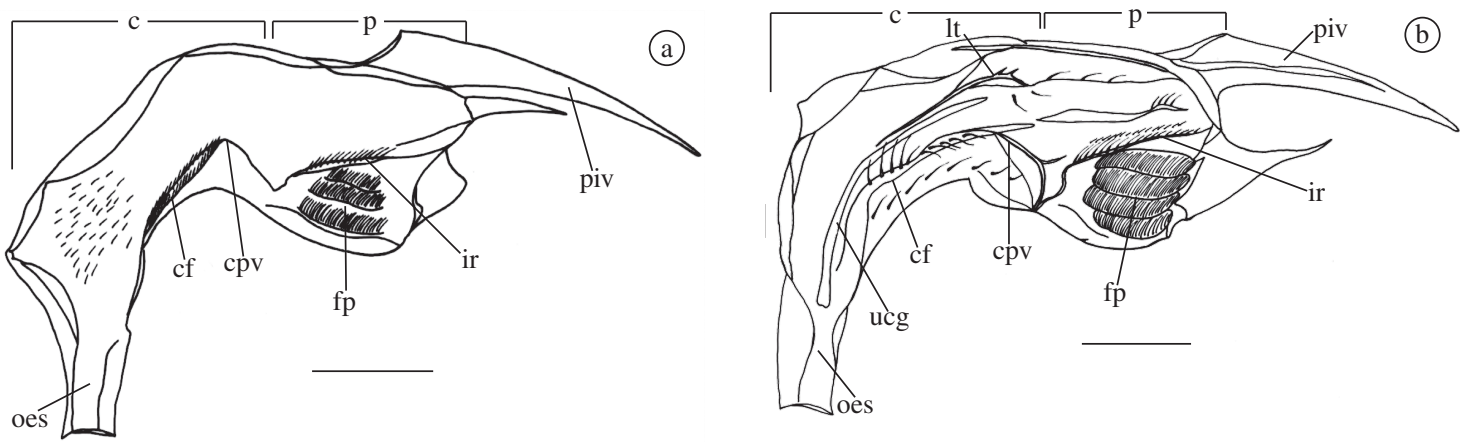

Figure 2. Litopenaeus vannamei, Foregut of larvae and post-larvae of mysis in lateral view (right side). a) mysis III (last larval stage); and b) juvenile I; scale bar $=0.05 \mathrm{~mm}$. Abbreviations: $\mathrm{c}=$ cardiac chamber; $\mathrm{cf}=$ cardiac chamber floor; $\mathrm{cpv}=\mathrm{cardi}$ opyloric valve; $\mathrm{fp}=$ filter press; ir = interampullary crista; $1 \mathrm{t}=$ lateral teeth $(\mathrm{a}$ pair); oes = oesophagus; $\mathrm{p}=$ pyloric chamber; piv = intestinal pyloric valve; $\mathrm{ucg}=$ cardiac superior gutter. 
arranged in rows in the interampullary crista; ampullary net functional.

\section{Megalopa (Figure 4)}

It was not possible to describe the foregut of this stage in detail, because the only obtained specimen was in moult process. However, it was possible to observe (Figure 4) the structure of the megalopa gastric mill inside of the new juvenile I foregut.

\section{Juvenile I (Figure 5)}

Foregut with ossicles of the gastric mill totally formed and apparently calcified; total length about $0.45 \mathrm{~mm}$.

Cardiac chamber: distended laterally; main brush of the gastric mill well-developed and apparently calcified having the zygocardiac (bearing the lateral teeth); urocardiac (bearing a strong medial tooth), mesocardiac, pterocardiac, propyloric, exopyloric and pyloric ossicles; other ossicles of lateral support are present such as, prepectinal (bearing the accessory teeth), postpectinal, lateral cardiopyloric valve and other not well-distinguished ossicles; valve cardiopyloric strong and specialized having many specified setae, hook shaped, disposed in the superior portion
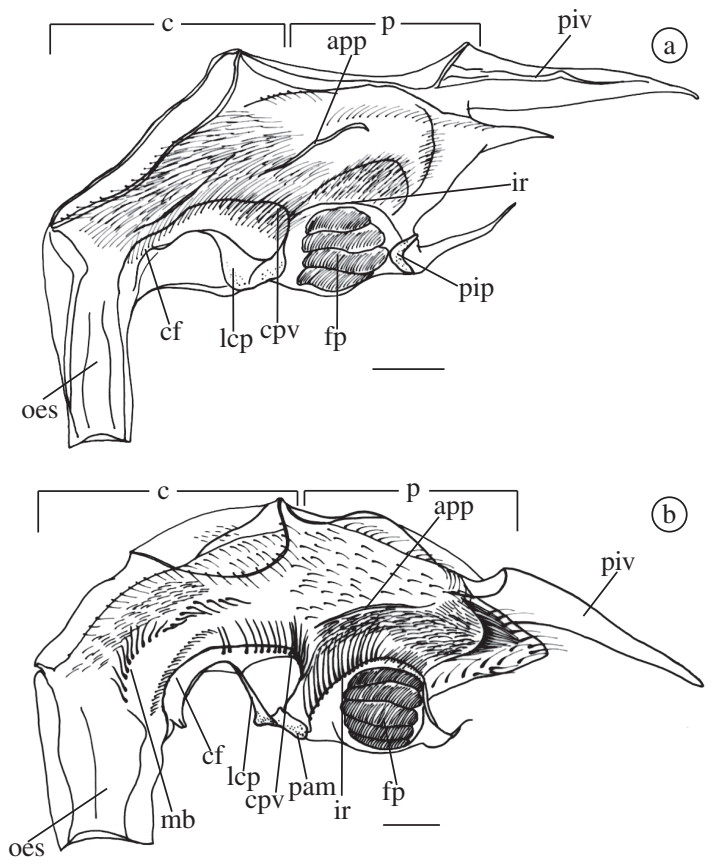

Figure 3. Callichirus major, foregut of larvae in lateral view (right side). a) zoea I; and b) zoea IV (last zoeal stage); scale bar $=0.05 \mathrm{~mm}$. Abbreviations: app = anterior pleuropyloric ossicle (a pair); $\mathrm{c}=$ cardiac chamber; $\mathrm{cf}=$ cardiac chamber floor; $\mathrm{cpv}=$ cardiopyloric valve; $\mathrm{fp}=$ filter press; ir = interampullary crista; lcp = lateral cardiopyloric valve ossicle (a pair); lt = lateral teeth (a pair); $m b=$ main brush (a pair); oes = oesophagus; $\mathrm{p}=$ pyloric chamber; pam = preampullary ossicle (a pair); pip = inferior posterior pyloric ossicle (one); piv = intestinal pyloric valve; ucg = cardiac superior gutter.
Pyloric chamber: elongate laterally with numerous setae in pyloric roof and in the anterior and posterior portions of the chamber; pyloric intestinal valve elongate; showing the anterior pleuropyloric, median pleuropy-

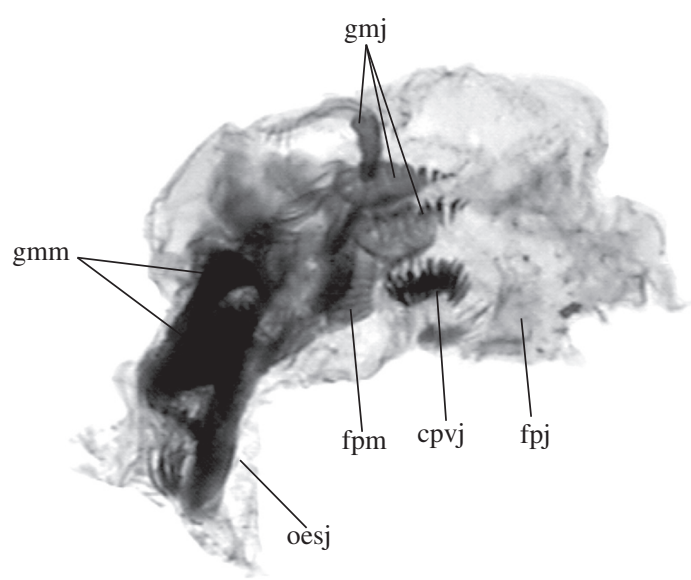

Figure 4. Callichirus major, foregut of the megalopa in moult process. Abbreviations: $\mathrm{cpvj}=$ cardiopyloric valve of the juvenile; $\mathrm{fpj}=$ filter press of the juvenile; fpm = filter press of the megalopa; gmj = gastric mill of the juvenile; gmm = gastric mill of the megalopa; oes $=$ oesophagus of the juvenile.

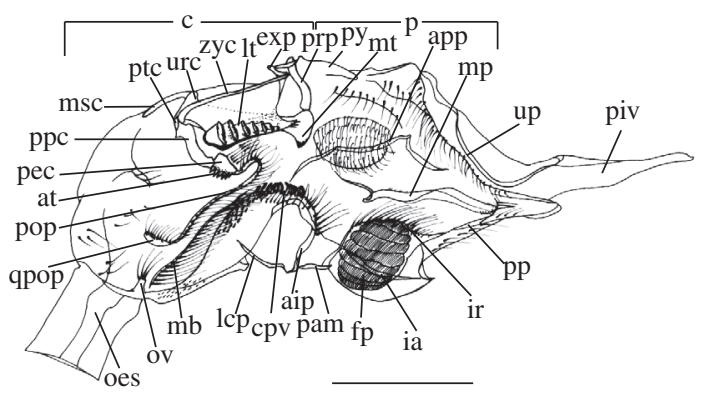

Figure 5. Callichirus major, foregut of a post-larvae in lateral view (right side); scale bar $=0.2 \mathrm{~mm}$ Abbreviations: aip = inferior anterior pyloric ossicle (one); app = anterior pleuropyloric ossicle (a pair); $\mathrm{c}=$ cardiac chamber; $\mathrm{cpv}=$ cardiopyloric valve; exp = exopyloric ossicle (a pair); fp = filter press; ia = inferior ampullary ossicle (a pair); ir = interampullary crista; $1 \mathrm{cp}=$ lateral cardiopyloric valve ossicle (a pair); lt = lateral teeth (a pair); $\mathrm{mb}=$ main brush (a pair); $\mathrm{mp}=$ median pleuropyloric ossicle $(\mathrm{a}$ pair $) ; \mathrm{msc}=$ mesocardiac ossicle (one); oes = oesophagus; ov = oesophageal valve; $\mathrm{p}=$ pyloric chamber; pam = preampullary ossicle (a pair); pec = pectinal ossicle (a pair); piv = intestinal pyloric valve; $p o p=$ postpectinal ossicle (um par); $p p=$ posterior pleuropyloric ossicle (a pair); ppc $=$ prepectinal ossicle (a pair); prp $=$ propyloric ossicle $($ one $) ;$ ptc $=$ pterocardiac ossicle (a pair); py = pyloric ossicle (one); qpop = "quill" of postpectinal ossicle (one pair); up = uropyloric ossicle (one, sometimes two fused); urc = urocardiac ossicle (one); zyc = zygocardiac ossicle (a pair). 
loric, posterior pleuropyloric, uropyloric, pre-ampullary, inferior ampullary and inferior anterior pleuropyloric ossicles; filter press well-developed, ampullary crista with a row of setae, ampullary net well complex.

\subsubsection{Sesarma rectum}

\section{Zoea I (Figure 6a)}

Foregut simple and chitinous; total length $0.25 \mathrm{~mm}$.

Cardiac chamber: with numerous fine setae on cardiac floor; cardiac wall lacking setae; cardiopyloric valve rounded and robust, with strong cylindrical setae in the posterior portion.

Pyloric Chamber: cardiac roof with fine setae in the posterior portion; filter press beehive-shaped, filling all inferior portion of the chamber; ampullary net incompletely developed, interampullary crista with rows of elongate setae.

\section{Zoea III (Figure 6b)}

Foregut more developed than that of the zoea I, but similar in shape, lacking rigid structures; total length $0.26 \mathrm{~mm}$.

Cardiac chamber: cardiac floor with a row of elongate and fine setae; cardiac wall slightly wrinkled with some setae in the anterior portion; cardiopyloric valve rounded, wide and armed with strong cylindrical setae in posterior portion.

Pyloric chamber: cardiac roof with fine setae in the posterior portion; filter press specialized and complex, filling all inferior portion of the chamber; ampullary net well-developed and functional; ampullary crista with row of elongate and medium setae.

\section{Megalopa (Figure 7a)}

Foregut having ossicles of the gastric mill, esophageal valve and other hard structure; total length $0.42 \mathrm{~mm}$.
Cardiac chamber: chamber enlarged dorsolaterally by the ossicles of the gastric mill; the cardiac floor disposed vertically; cardiopyloric valve specialized and robust. The ossicles of the gastric mill are present, such as: mesocardiac, pterocardiac, zygocardiac (bearing the lateral teeth), urocardiac (bearing the tooth medial), propyloric, exopyloric and pyloric. Other ossicles are also found as: prepectinal, pectinal, postpectinal, subdentate, lateral cardiac inferior, lateral of the valve cardiopyloric and anterior supraampullary.

Pyloric chamber: narrow laterally with fine setae in the posterior portion of the cardiac roof; filter press specialized with the ampullary net well-developed and functional; interampullary crista with rows of elongate setae; some important ossicles present, such as: anterior pleuropyloric, posterior pleuropyloric, medium pleuropyloric, preampullary and inferior posterior pyloric.

\section{Juvenile I (Figure 7b)}

Foregut more specialized than megalopa stage, total length about $0.54 \mathrm{~mm}$.

Cardiac chamber: gastric mill showing a group of well-developed articulated ossicles; cardiopyloric valve specialized bearing some denticles and several setae in the superior portion. The zygocardiac and urocardiac ossicles supporting teeth more distinct and capable to the mastigatory processes. The ossicles prepectinal and pectinal showing the accessory teeth spiny shaped. Other ossicles similar to the megalopa foregut.

Pyloric chamber: similar to the previous stage with setae in the posterior portion of the roof; filter press well developed with the ampullary net developed and functional; interampullary crista with rows of setae; the ossicle inferior anterior pyloric and uropyloric are present; other ossicles without significant morphological alterations.
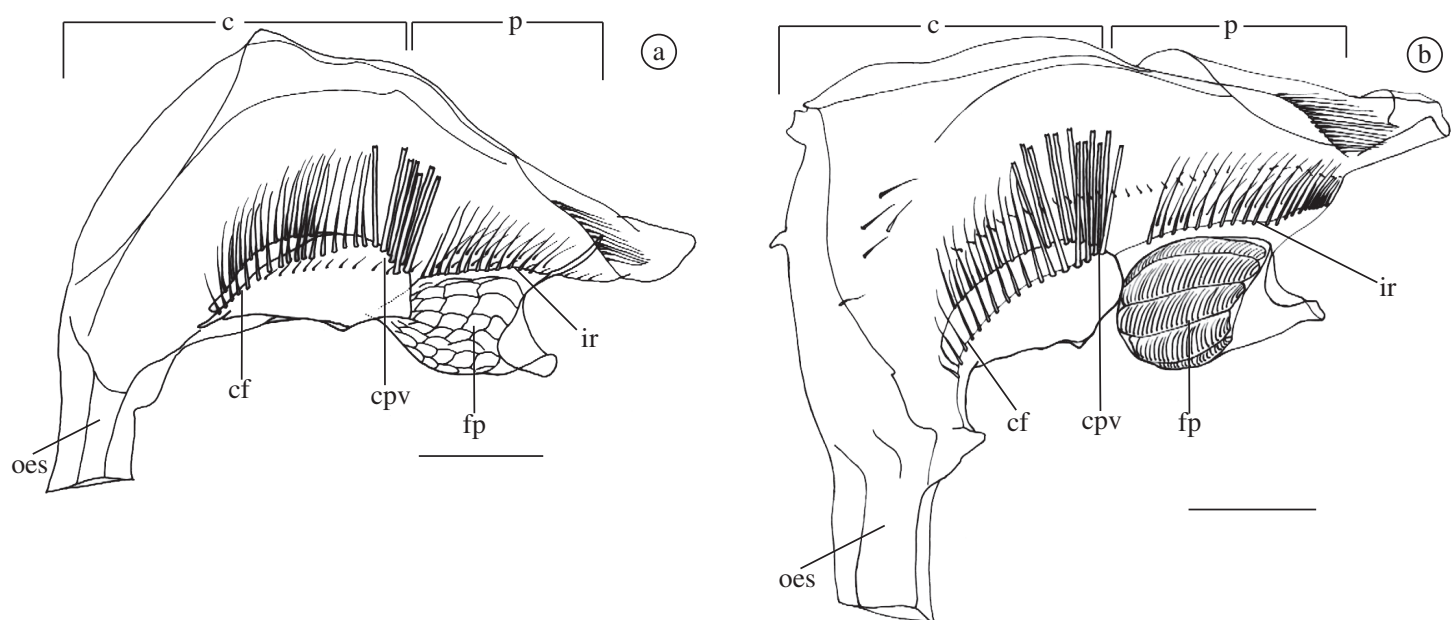

Figure 6. Sesarma rectum, foreguts of larvae in lateral view (right side). a) zoea I; and b) zoea III (last zoea); scale $=0.05 \mathrm{~mm}$. Abbreviations: $\mathrm{c}=$ cardiac chamber; $\mathrm{cf}=$ cardiac chamber floor; $\mathrm{cpv}=$ cardiopyloric valve; $\mathrm{fp}=$ filter press; ir $=$ interampullary crista; oes = oesophagus; $\mathrm{p}=$ pyloric chamber. 

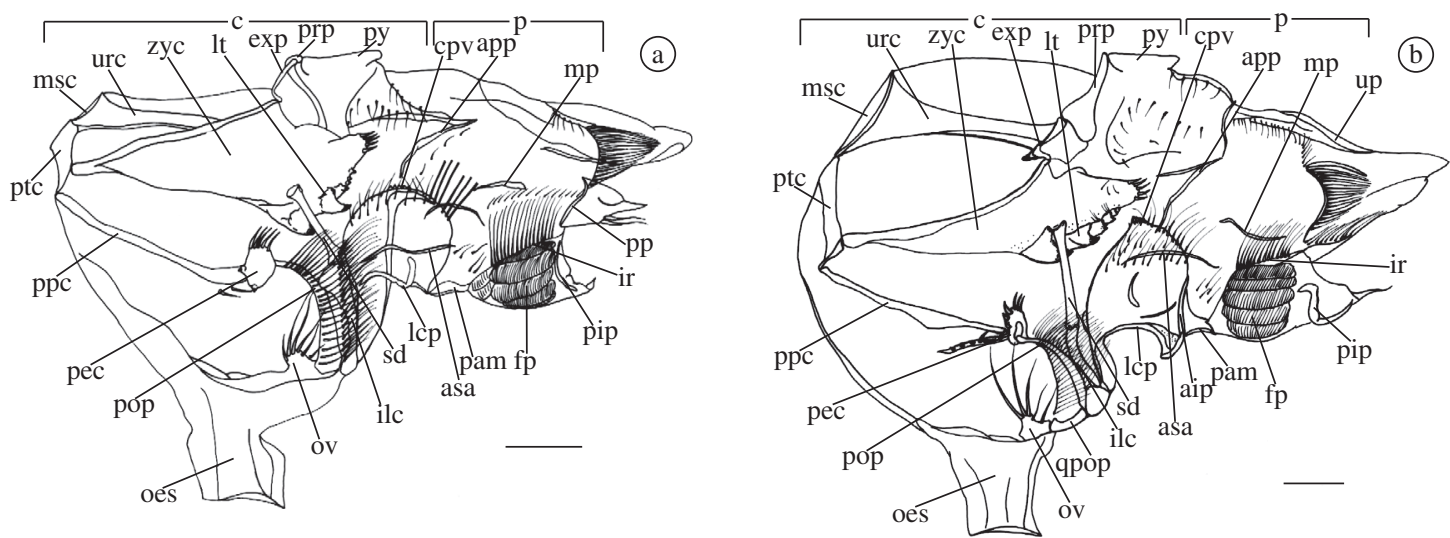

Figure 7. Sesarma rectum, foreguts of megalopa and juvenile I in lateral view (right side). a) megalopa; b) juvenile I; scale bar $=0.05 \mathrm{~mm}$. Abbreviations: aip = inferior anterior pyloric ossicle (one); app = anterior pleuropyloric ossicle (a pair); asa = anterior supra-ampullary ossicle (a pair); $\mathrm{c}=$ cardiac chamber; $\mathrm{cpv}=$ cardiopyloric valve; $\mathrm{exp}=$ exopyloric ossicle (a pair); $\mathrm{fp}=$ filter press; ilc = lateral inferior cardiac ossicle (a pair); ir = interampullary crista; lcp = lateral cardiopyloric valve ossicle (a pair; $1 \mathrm{t}=$ lateral teeth (a pair); $\mathrm{mp}=$ median pleuropyloric ossicle (a pair); msc = mesocardiac ossicle (one); oes = oesophagus; $\mathrm{ov}=$ oesophageal valve; $\mathrm{p}=$ pyloric chamber; pam = preampullary ossicle (a pair); pec = pectinal ossicle (a pair); pip = inferior posterior pyloric ossicle (one); pop = postpectinal ossicle (um par); $\mathrm{pp}=$ posterior pleuropyloric ossicle (a pair); $\mathrm{ppc}=$ prepectinal ossicle $(\mathrm{a}$ pair $) ; \mathrm{prp}=$ propyloric ossicle $($ one $) ; \mathrm{ptc}=$ pterocardiac ossicle $(\mathrm{a}$ pair $) ; \mathrm{py}=$ pyloric ossicle $($ one $) ;$ qpop = "quill" of postpectinal ossicle (one pair); sd = subdentate ossicle (a pair); up = uropyloric ossicle (one, sometimes two fused); urc = urocardiac ossicle (one); zyc = zygocardiac ossicle (a pair).

\section{Discussion}

The nauplii of peneid species are considered a nonfeeding larval stage, in which they require no external food to complete their development to protozoea stage. In $L$. setiferus, the wall of the foregut of the $5^{\text {th }}$ naupliar substage is very compressed and the lumen is absent. Due to this fact the organism does not permit the ingestion of food particles. After moulting to the protozoea stage this organ becomes functional (Lovett and Felder, 1989). In the present study, unfortunately, it was not possible to observe the foregut of protozoea I, L. vannamei. Despite the fact that the protozoea III foregut of $L$. vannamei is very simple, the distinct structures in the ventral region of the foregut indicate that differentiated functions occur. Numerous setae are observed in the walls of the two chambers indicating alimentary particles of microalgae or other kind of food similar in size and flexibility.

After moulting to mysis stage, the larvae become actively carnivore and this behaviour is continued in subsequent postlarvae and adult stages (Jones et al., 1993). The foregut of this stage clearly appears specialized by the appearance of a visibly functional cardiopyloric valve and filter press (Figures $1 b$ and $2 a$ ). These morphological characteristics strongly suggest that mysis of $L$. vannamei are capable of eating more diversified foods, as Artemia, rotifers, etc. On the other hand, Kumlu (1999) related that the gastric mill is completely developed in the stomach of the mysis and these structures increase the carnivorous capacity of the larva, as well as the food retention and assimilation of energy. However, these observations do not agree with the morphological features found in the present study (Figures 1b and 2a) nor those reported for $L$. setiferus by Lovett and Felder (1989).

The foregut of the juvenile I (first post-larva) of L. vannamei increases in complexity after metamorphosis, showing some rigid structures and a well-developed filter press. But, such alterations are not considerably significant if compared to those decapods such as lobster and crab (Nishida et al., 1990; Abrunhosa et al., 2003). The ossicles of the peneid juveniles are gradually formed after establishment of the bentonic life (Lovett and Felder, 1989). This fact agrees with our observation that ossicles, lightly calcified, are verified in the foregut of the juvenile I. Nevertheless, the possibility of juvenile I processing great amounts of several types of food naturally found in the bentonic environment are not eliminated.

The foreguts of $L$. siriboia (described by Abrunhosa et al., 2006) and C. major larvae (present study) are rather different during their development. $C$. major shows a developed foregut bearing setae and some ossicles, while in L. siriboia these structures are entirely absent. But, after the metamorphosis into megalopa the foreguts of these species become similar in shape having a complex gastric mill.

The foregut of the $C$. major larvae is morphologically specialized and functional. In the zoea I a considerable number of setae and some rigid structures are observed and the filter press is completely developed (Figure 3a). These characteristics are not commonly found in decapod larvae. Moreover, an increase in specialization occurs in the foregut during the larval development with an increment of strong setae in the car- 
diopyloric valve, main brush and interampullary crista (Figure 3b).

The external feeding appendages of the early zoeal stages of $C$. major described by Rodrigues (1976) show setae and spines in the endopods of the maxillules and maxillae and, numerous setae in the maxillipeds. These structures are not found in the zoeae of $L$. siriboia (Abrunhosa et al., 2006), showing that a considerable variation exists in the feeding behaviour of shrimp larvae.

The complexity of the external and internal feeding appendages during the larval development of $C$. major indicates that these larvae are well suited for feeding both phytoplankton and zooplankton and, most likely cannot metamorphose into megalopa stage without feeding.

Although the megalopa of $C$. major observed in this study was in process of moulting and some internal structure of the foregut was not clearly visible, evidence of a well-developed gastric mill was observed (Figure 4). This indicates that the megalopa of $C$. major is capable to eat hard food materials. After moulting into juvenile I stage, the foregut of $C$. major (Figure 5) showed morphologically similar to that of $L$. siriboia described by Abrunhosa et al. (2006) and probably has similar feeding behaviors.

The grapsids $S$. curacaoense (described by Melo et al., 2006) and $S$. rectum (present study) show morphologic similarity in the foregut from larval to the juvenile stages. Both species hold specific setae in the cardiopyloric valve and filter press, which is characteristic of most decapod zoeae.

Fransozo and Hebling (1986) verified increasing and specialization in the feeding appendages during the development of $S$. rectum by the presence of setae and spines in the endopods of the maxillae and maxillipeds. The $S$. rectum also shows also a foregut with functional structures (Figures 6a and b). In the last larval stage (zoea III), the ability to process small food particles increases because of the increment in the size of the foregut and the number of setae (Figure 6b). These facts coincide with studies accomplished on crab larvae (Shinkarenko, 1979; Factor, 1982; Minagawa and Takashima, 1994; Abrunhosa et al., 2003).

The foregut of the $S$. rectum megalopa makes an abrupt morphological change after metamorphosis. Complex ossicles appear compounding the gastric mill. The lateral teeth and a strong and calcified medial, as well as other important ossicles are observed in the foregut of the stomach (Figure 7a). The presence of these structures indicates that they feed on hard particles of food. Similar observations were noted for the species Ucides cordatus (Linnaeus, 1763) (Abrunhosa et al., 2003).

Fransozo and Hebling (1986) also verified that mandibles of the megalopae bear a chitinous blade and the maxillae and maxillipeds are very setose and developed. The capacity to cut food with the mandibles and the mastigatory function of the foregut indicates that small ben- tonic organisms, such as mollusks and small crustaceans, can be eaten by the megalopas of $S$. rectum.

In the stomach of the $S$. rectum juvenile I the lateral and medial teeth of the gastric mill are more specialized than that of the megalopa (Figure $7 \mathrm{~b}$ ) resembling adults crab of brachyura previously described in other studies (Meiss and Norman, 1977; Skilleter and Anderson, 1986; Martin et al., 1998; Brösing et al., 2002). This indicates that juvenile I should inhabit similar substratum and they are capable of eating a rich diet of soft and hard foods, which are commonly found in the bentonic environment.

\section{References}

ABRUNHOSA, FA. and KITTAKA, J., 1997a. Functional morphology of mouthparts and foregut of the last zoea, glaucothoe and first juvenile of the king crabs Paralithodes camtschaticus, P. brevipes and P. platypus. Fisheries Science, vol. 3, no. 6, p. 923-930.

-, 1997b. Morphological changes in the midgut, midgut gland and hindgut during the larval and postlarval development of the red king crab Paralithodes camtschaticus. Fisheries Science, vol. 63 , no. 5 , p. $746-754$.

ABRUNHOSA, FA., MELO, MA. and ABRUNHOSA, J. P., 2003. Development and functional morphology of the foregut of larvae and postlarva of Ucides cordatus (Decapoda, Ocypodidae). Nauplius, vol. 11, no. 1, p. 37-43.

ABRUNHOSA, F., MELO, M., LIMA, JF. and ABRUNHOSA, J., 2006. Developmental morphology of mouthparts and foregut of the larvae and postlarvae of Lepidophthalmus siriboia Felder and Rodrigues, 1993 (Decapoda: Callianassidae). Acta amazônica, vol. 36, no. 3, p. 335-342.

BRÖSING, A., RICHTER, S. and SCHOLTZ, G., 2002. The foregut-ossicle system of Dromia wilsoni, Dromia personata and Lauridromia intermedia (Decapoda, Brachyura, Dromiidae), studied with a new staining method. Arthr. Struct. Develop., vol. 30, p. 329-338.

CASTRO, TS. and BOND-BUCKUP, G., 2003. The morphology of cardiac and pyloric foregut of Aegla platensis Schmitt (Crustacea: Anomura: Aeglidae). Mem. Mus. Vict., vol. 60, no. 1, p. 53-57.

FACTOR, JR., 1982. Development and metamorphosis of the feeding apparatus of the stone crab, Menippe mercenaria (Brachyura, Xanthidae). J. Morph., vol. 172, p. 299-312.

FRANSOZO, A. and HEBLING, NJ., 1986. Desenvolvimento larval de Sesarma (Holometopus) rectum Randall, 1840 (Decapoda, Grapsidae), em laboratório. Rev. Bras. Biol., vol. 46, no. 2, p. 353-364.

JHA, A. and HOMECHAUDHURI, S., 2001. Understanding the gastric mill structure of a macrophagous shrimp Metapenaeus monoceros (Fabricius). Current Science, vol. 80, no. 5, p. 620-622.

JONES, DA., KAMARUDIN, MS. and LE VAY, L., 1993. The potential for replacement of live feeds in larval culture. J. World Aquac. Society, vol. 24, no. 2, p. 199-210.

KITTAKA, J., 1988. Culture of the palinurid Jasus lalandii from egg to puerulus. Nippon Suisan Gakkaishi, vol. 54, no. 1, p. 87-93. 
KITTAKA, J. and IKEGAMI, E., 1988. Culture of palinurid Panulirus elephas from egg stage to puerulus. Nippon Suisan Gakkaishi, vol. 54, no. 7, p. 1149-1154.

KITTAKA, J., 1994. The biology and management of lobsters. Academic. New York and London, Academic Press. 463 p.

KITTAKA, J., ONO, K. and BOOTH, JD., 1997. Complete development of the green rock lobster Jasus verreauxi from egg to juvenile stage. Bull. Mar. Sci., vol. 6, p. 57-71.

KUMLU, M., 1999. Feeding and digestion in larval decapod crustaceans. Turk. J. Biol., vol. 2, no. 3, p. 215-229.

KUNZE, J. and ANDERSON, DT., 1979. Functional morphology of the mouthparts and gastric mill in the hermit crab Clibanarius taeniatus (Milne Edwards), Clibanarius virescens (Krauss), Paguristes squamosus McCulloch and Dardanus setifer (Milne Edwards) (Anomura: Paguridae). Austr. J. Mar. Fresh. Res., vol. 30, p. 683-722.

LEMMENS, JWTJ. and KNOTT, B., 1994. Morphological changes in external and internal feeding structures during the transition phyllosoma-puerulus-juvenile in the western rock lobster (Panulirus cygnus, Decapoda: Palinuridae). J. Morph., vol. 220, p. 271-280.

LOVETT, DL. and FELDER, DL., 1989. Ontogeny of gut morphology in the white shrimp Penaeus setiferus (Decapoda: Penaeidae). J. Morph., vol. 20, no. 1, p. 253-272.

MARTIN, JW., JOURHARZADEH, P. and FITTERER, PH., 1998. Description and comparison of major foregut ossicles in hydrothermal vent crabs. Mar. Biol., vol. 131, p. 259-267.

MEISS, DE. and NORMAN, RS., 1977. Comparative study of the stomatogastric system of several decapod Crustacea. $J$. Morph., vol. 152, p. 21-54.

MELO, AM., ABRUNHOSA, FA. and SAMPAIO, I., 2006. The morphology of the foregut of larvae and postlarva of Sesarma curacaoense De Man, 1892: a species with facultative lecithotrophy during larval development. Acta amazonica, vol. 36 , no. 3, p. 375-380.
MIKAMI, S. and TAKASHIMA, F., 1993. Development of the proventriculus in larvae of the slipper lobster, Ibacus ciliatus (Decapoda, Scyllaridae). Aquaculture, vol. 116, p. 199-217.

MINAGAWA, M. and TAKASHIMA, F., 1994. Developmental changes in larval mouthparts and foregut in the red frog crab, Ranina ranina (Decapoda: Raninidae). Aquaculture, vol. 126, p. 61-71.

NISHIDA, S., QUIGLEY, BD., BOOTH, JD., NEMOTO, T. and KITTAKA, J., 1990. Comparative morphology of the mouthparts and foregut of the final stage phyllosoma, puerulus, and postpuerulus of the rock lobster Jasus edwardsii (Decapoda: Palinuridae). J. Crust. Biol., vol. 10, p. 293-305.

PINN, EH., NICKELL, LA., ROGERSON, A. and ARKINSON, RJA., 1999. Comparison of gut morphology and gut microflora of seven species of mud shrimp (Crustacea: Decapoda: Thalassinidea). Mar. Biol., vol. 133, p. 103-114.

RODRIGUES, SA., 1976. Sobre a reprodução, embriologia e desenvolvimento larval de Callichirus major Say, 1818 (Crustacea, Decapoda, Thalassinidea). Bol. Zool., vol. 1 p. $85-104$

SHINKARENKO, L., 1979. Development of the larval stages of the blue swimming crab L. (Portunidae: Decapoda: Crustacea). Aust. J. Mar. Freshwater Res., vol. 30, p. 485-503.

SKILLETER, GA. and ANDERSON, DT., 1986. Functional morphology of the chelipeds, mouthparts and gastric mill of Ozius truncates (Milne Edwards) (Xanthidae) and Leptograpsus variegatus (Fabricius) (Grapsidae) (Brachyura). Aust. J. Mar. Freshwater Res., vol. 37, p. 67-79.

SUTHERS, IM., 1984. Functional morphology of the mouthparts and gastric mill in Penaeus plebejus Hess (Decapoda: Penaeidea). Aust. J. Mar. Freshwater Res., vol. 35, p. 785-792.

WOLFE, SH. and FELGENHAUER, BE., 1991. Mouthpart and foregut ontogeny in larval, postlarval, and juvenile spiny lobster Panulirus argus Latreille (Decapoda: Palinuridae). Zool. Scripta, no. 20, p. 57-75. 